\title{
One size does not fit all: differences in quality of life and survivorship among lung, colon, breast and prostate cancer patients
}

\author{
Leah M Backhus ${ }^{1,2 *}$, Steven B Zeliadt ${ }^{3,4}$, Lynn Reinke ${ }^{3,6}$, Tessa Rue ${ }^{5}$ and David H Au ${ }^{6}$ \\ ${ }^{1}$ VA Palo Alto Health Care System, Surgery Service, Palo Alto, Canada \\ ${ }^{2}$ Department of Cardiothoracic Surgery, Stanford University, USA \\ ${ }^{3}$ VA Puget Sound Health Care System, Health Services Research \& Development Service, Seattle, WA, USA \\ ${ }^{4}$ Department of Health Services, School of Public Health, University of Washington, USA \\ ${ }^{5}$ Department of Biostatistics, School of Public Health, University of Washington, USA \\ ${ }^{6}$ Department of Medicine, Division of Pulmonary and Critical Care, University of Washington, USA
}

\begin{abstract}
Purpose: Advances in treatment have led to a growing population of cancer survivors. Few interventions for cancer survivorship care utilize a tailored approach by cancer type. We examined differences for ongoing needs and survivorship care among a national sample of cancer survivors.

Methods: Data was obtained from the 2010 Cancer Control Supplement of the National Health Interview Survey for breast, prostate, colon, and lung cancer respondents. Health status and needs were examined using ordinal logistic regression.

Results: Lung cancer patients reported fair or poorer quality of life (QOL) for 39\% of respondents compared to colon (18\%), breast (11\%), and prostate (9\%). After adjustment for age and marital status, all cancer types reported better QOL compared to lung cancer survivors (colon OR 2.03 [95\% CI 0.88-4.66] breast OR 3.59 [95\% CI 1.55-8.33] and prostate OR 2.97 [95\% CI 1.28-6.91]). Lung cancer patients reported significantly more financial problems compared to all other cancer types (colon OR 0.46 [95\% CI 0.24-0.87] breast OR 0.45 [95\% CI 0.25-0.81] and prostate OR 0.30 [95\% CI 0.16-0.56]).
\end{abstract}

Conclusion: Cancer survivorship needs and quality of life differ significantly depending on caner type which emphasizes the importance of a tailored approach to cancer survivorship care.

\section{Introduction}

In 2012, there were 13.7 million Americans living with cancer. Given advancements in cancer detection and improved treatments, this number is expected to rise to 18 million by the year 2022 [1]. While advances in medicine have produced the desired result of increased survival, many treatments carry undesired side effects and lead to longterm sequelae that should be addressed. Many survivors report ongoing needs that require additional intervention or monitoring that are not currently being met. Recently there has been a groundswell of support for cancer survivors in recognizing both their needs and growing numbers [2]. This patient-centered approach to cancer survivorship care is supported by many organizations including the American College of Surgeons Commission on Cancer (CoC), the American Cancer Society, the National Coalition for Cancer Survivorship, the Cancer Support Community, and the LIVESTRONG Foundation. In 2011, the CoC set forth new accreditation standards for hospital cancer programs that include recommendations for comprehensive cancer survivorship care for the transition from active treatment to long-term care [3]. Specifically, the $\mathrm{CoC}$ has also mandated incorporation of a survivorship care plan that summarizes treatment and care received and recommendations for follow-up. All efforts are aimed at improving the quality of life for cancer survivors.
Much of the work on cancer survivorship has been focused on comparing needs of cancer survivors to those of patients without cancer or with chronic conditions. The majority of these studies have examined the needs of breast cancer survivors with little comparison between cancer types [4-7]. Few studies have attempted to apply lessons learned in the care of breast cancer patients to survivors of other cancer types with mixed results.

We hypothesized that survivors of different cancer types may experience significant differences in transitioning from active care to long-term survivorship that might help to inform future interventions.

\section{Methods}

\section{Data source}

Data were obtained from the National Health Interview Survey

Correspondence to: Leah M. Backhus, Department of Cardiothoracic Surgery, Stanford University, 300 Pasteur Drive, Stanford, CA 94304, Canada, Tel: 650721-6400; E-mail: lbackhus@stanford.edu

Received: January 24, 2016; Accepted: February 22, 2016; Published: February 26,2016 
(NHIS) conducted by the Center for Disease Control and the National Center for Health Statistics. [National Center for Health Statistics. National Ambulatory Medical Survey, 1994]. NHIS is a crosssectional household survey among US residents with continuous sampling throughout the year. Data are divided into core and supplemental surveys. The Cancer Control Supplement contained responses regarding diet and nutrition, physical activity, tobacco use, cancer screening, genetic testing, and family history. In 2010, cancer survivorship was added as a section to the Cancer Control Supplement. We used the 2010 survey results with demographic data obtained from the Core survey and cancer survivorship responses contained in the Cancer Control Supplement. Our cohort was defined as respondents with a self-reported history of breast, prostate, colon, or lung cancer who completed the Cancer Control Supplement.

\section{Analysis}

Our main exposure variable was type of cancer reported and demographic characteristics. Primary outcomes included quality of life, ongoing concerns, and survivorship care planning as reported in the survivorship question module. We performed unadjusted analyses with comparisons between cancer types using Chi-square test with $\mathrm{p}<$ 0.05 significance level. Adjusted analyses were performed using ordinal logistic regression with two models fitted to the data. One model adjusted for age, gender (colon and lung cancer only), and marital status. In addition to these, a second model adjusted for whether or not respondents had been diagnosed with a recent recurrence, whether or not they had surgery as their primary cancer treatment, and if they had undergone treatment within the past 12 months. Statistical analyses were performed using SAS (SAS Institute Inc).

\section{Results}

There were a total of 838 respondents with a history of breast, prostate, colon, or lung cancer (breast $n=398$, prostate $n=255$, colon $\mathrm{n}=151$, lung $\mathrm{n}=60)$. The majority of respondents were white $(85 \%)$ and aged 55-74 years for all cancer types. Lung cancer patients had the highest percentage of patients diagnosed within the most contemporary time frame of 2006-2010 (92\%) (Table 1). On unadjusted analyses, breast and prostate cancer patients reported the highest percentage of excellent quality of life (33\% and $31 \%$ respectively) compared to colon $(21 \%)$ and lung $(19 \%)$ cancer patients $(\mathrm{p}<0.005)$. Physical health status was also reported as excellent for a larger proportion of breast and prostate cancer patients ( $12 \%$ and $14 \%$ respectively) compared to either colon (9\%) or lung $(10 \%)$ cancer patients $(\mathrm{p}<0.005)$. The degree that cancer caused financial problems was highest among lung cancer patients (25\%) compared to all other cancer types (colon $11 \%$, breast $12 \%$, prostate $4 \%)(\mathrm{p}<0.005)$. Overall, only $36 \%$ of cancer patients received a written treatment summary following completion of their therapy. Lung cancer patients reported the lowest rate of receipt of treatment summary (20\%). There were no significant differences between self-reported mental health status according to cancer type (Figure 1A-1C).

After adjustment for age and marital status, the odds for better

Table 1. Demographics.

\begin{tabular}{|c|c|c|c|c|c|c|}
\hline & \multicolumn{2}{|c|}{ Any of 4 cancers } & \multirow{2}{*}{$\begin{array}{l}\text { Breast } \\
\%(w t)\end{array}$} & \multirow{2}{*}{$\begin{array}{c}\text { Prostate } \\
\%(w t)\end{array}$} & \multirow{2}{*}{$\begin{array}{l}\text { Colon } \\
\% \text { (wt) }\end{array}$} & \multirow{2}{*}{$\begin{array}{r}\text { Lung } \\
\%(w t)\end{array}$} \\
\hline & $\mathrm{N}$ & $\%(w t)$ & & & & \\
\hline Total & 926 & & 439 & 284 & 164 & 67 \\
\hline \multicolumn{7}{|l|}{ Sex } \\
\hline Male & 372 & 44.5 & 1.3 & 100 & 49.6 & 39.7 \\
\hline Female & 554 & 55.5 & 98.7 & & 50.4 & 60.3 \\
\hline \multicolumn{7}{|l|}{ Race } \\
\hline White & 709 & 84.7 & 84.9 & 84.9 & 85 & 82.1 \\
\hline Black & 162 & 10.5 & 9.7 & 11 & 10.1 & 12 \\
\hline $\mathbf{A I} / \mathbf{A N *}$ & 9 & 1.2 & 0.9 & 2.3 & & \\
\hline Asian & 34 & 2.5 & 3.2 & 1.7 & 3.1 & 2.5 \\
\hline Multiple & 12 & 1.2 & 1.3 & 0.1 & 1.8 & 3.4 \\
\hline \multicolumn{7}{|l|}{ Age } \\
\hline $18-34$ & 5 & 0.5 & 0.5 & 0.4 & 1.2 & 0 \\
\hline $35-54$ & 125 & 13.5 & 20.5 & 2.8 & 13.4 & 10.4 \\
\hline $55-74$ & 441 & 47.6 & 47.8 & 49.3 & 40.9 & 49.3 \\
\hline $75+$ & 355 & 38.3 & 31.2 & 47.5 & 44.5 & 40.3 \\
\hline \multicolumn{7}{|l|}{ Marital status } \\
\hline Married & 436 & 61.2 & 50.7 & 77.7 & 58 & 56.6 \\
\hline Widowed & 246 & 18.6 & 24.4 & 10 & 18.6 & 24 \\
\hline Divorced & 145 & 11.4 & 15.9 & 4.8 & 10.7 & 15.6 \\
\hline Separated & 21 & 1.4 & 2.1 & 1.4 & 0.8 & 0.4 \\
\hline Never Married & 58 & 4.2 & 4.2 & 3.7 & 5.7 & 1.4 \\
\hline Living with Partner & 20 & 3.2 & 2.7 & 2.3 & 6.3 & 1.9 \\
\hline \multicolumn{7}{|l|}{ Year of most recent recurrence } \\
\hline 1962-1994 & 4 & 4.9 & 6.5 & 9.1 & 0.0 & 0.0 \\
\hline 1995-2000 & 9 & 11.1 & 9.7 & 13.6 & 10.5 & 0.0 \\
\hline 2001-2005 & 12 & 14.8 & 16.1 & 13.6 & 15.8 & 7.7 \\
\hline 2006-2010 & 56 & 69.1 & 67.7 & 63.6 & 73.7 & 92.3 \\
\hline
\end{tabular}


A-C
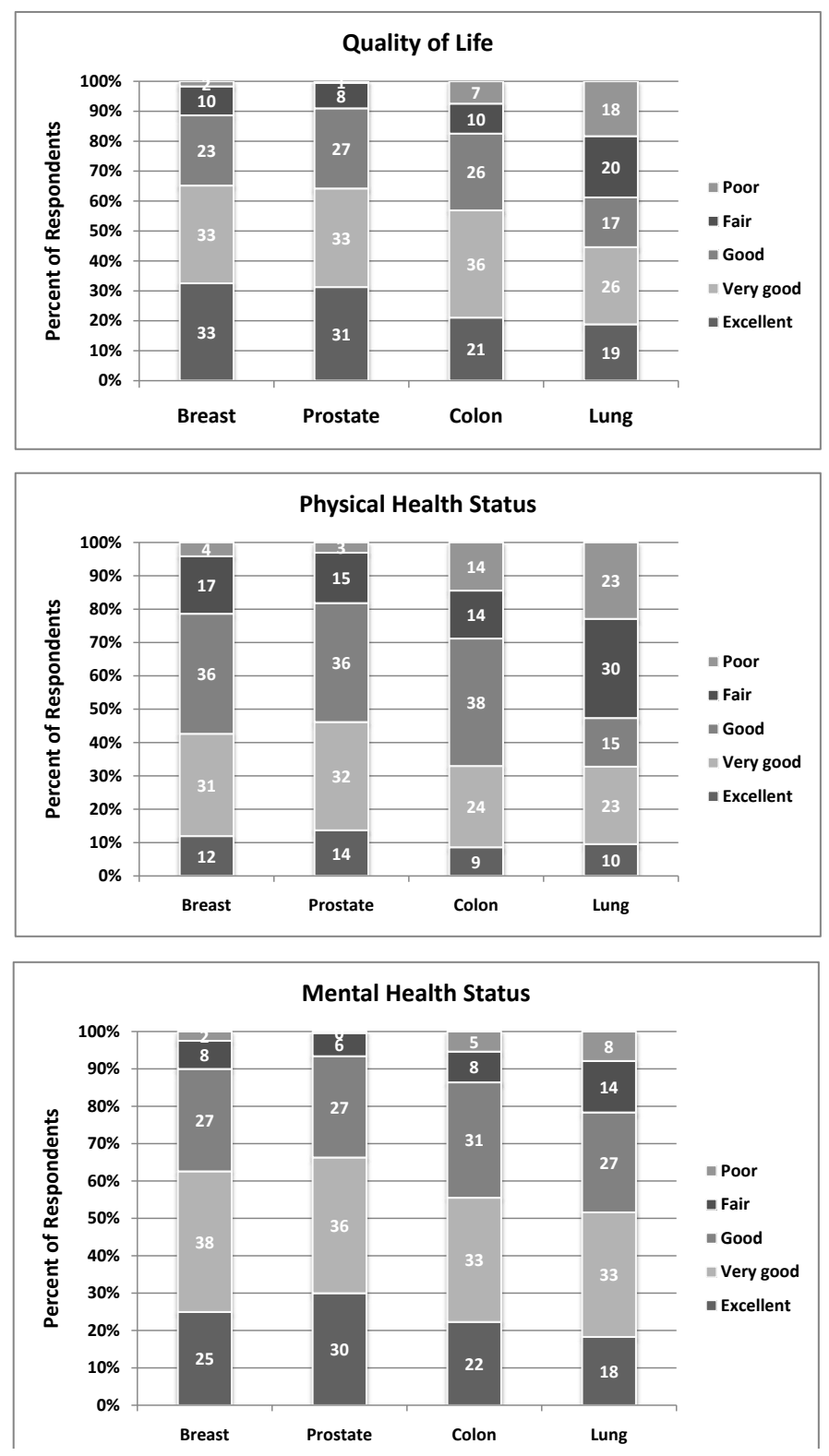

Figure 1. Unadjusted survey responses.

quality of life were higher for all cancer types compared to lung cancer survivors (colon OR 2.03 [95\% CI 0.88-4.66] breast OR 3.59 [95\% CI 1.55-8.33] and prostate OR 2.97 [95\% CI 1.28-6.91]) (Figure 2). Lung cancer patients also reported significantly higher degree of financial problems compared to all other cancer types (colon OR 0.46 [95\% CI 0.24-0.87] breast OR 0.45 [95\% CI 0.25-0.81] and prostate OR 0.30 [95\% CI 0.16-0.56]). After full adjustment lung cancer survivor quality of life was only significantly lower than breast cancer survivors (OR 3.24 [95\% CI 1.19-8.78]) (Table 2).

\section{Discussion}

It is well-documented that patients with a history of cancer experience overall poorer quality of life compared to those without cancer $[8,9]$ There are many reasons for this including older age among cancer patients and pre-existing comorbidities that may be exacerbated in the setting of acute cancer treatment [10,11]. Other risk factors for lower heath related quality of life among cancer survivors compared to non-cancer patients include Black or Hispanic ethnicity, low income, and low education level [12-15]. Few studies have made direct comparisons between cancer types regarding ongoing survivorship needs. Lung cancer has been associated with a higher symptom burden and lower health utility scores compared to survivors of other cancer types [16,17]. We focused on comparisons between the four most prevalent cancers within a large national sample in an effort to better understand potential differences in designing survivorship care interventions. We found that reported physical health status varied significantly by cancer type with lung cancer survivors reporting the lowest scores. Some of these observed differences may be due the aforementioned risk factors that disproportionately affect patients with lung cancer including age, comorbidity, and social factors. For instance, we were unable to account for smoking as a covariate and smoking has been associated with significantly lower quality of life regardless of cancer status [18]. We were, however able to account for two other important variables in our multivariable analysis, namely time since treatment and surgery as a primary treatment. In doing so, the differences between cancer types was attenuated which likely underscores the importance of specific treatment-associated morbidity in influencing cancer survivor needs.

Other studies have demonstrated a higher use of mental health services among cancer survivors as well as other emotional needs compared to patients without cancer $[19,20]$. We found that selfreported mental health or fear of cancer recurrence did not differ significantly among the different cancer types. We did, however note that lung cancer patients experienced greater financial hardship compared to survivors of other cancer types. The unemployment rate among cancer survivors has been reported to be twice that of noncancer controls ranging from $18-33 \%$ with another $11 \%$ reporting that they have been denied healthcare coverage due to their medical condition [5,9]. Even after accounting for age, the financial burden reported by lung cancer patients remained significantly higher at least compared to prostate cancer survivors.

The most basic element of cancer survivorship is potentially the inclusion of a survivorship care plan (SCP). According to both the Institute of Medicine (IOM) and the $\mathrm{CoC}$, a survivorship care plan should include among other things, a written treatment summary. A study among National Cancer Institute (NCI)-designated cancer

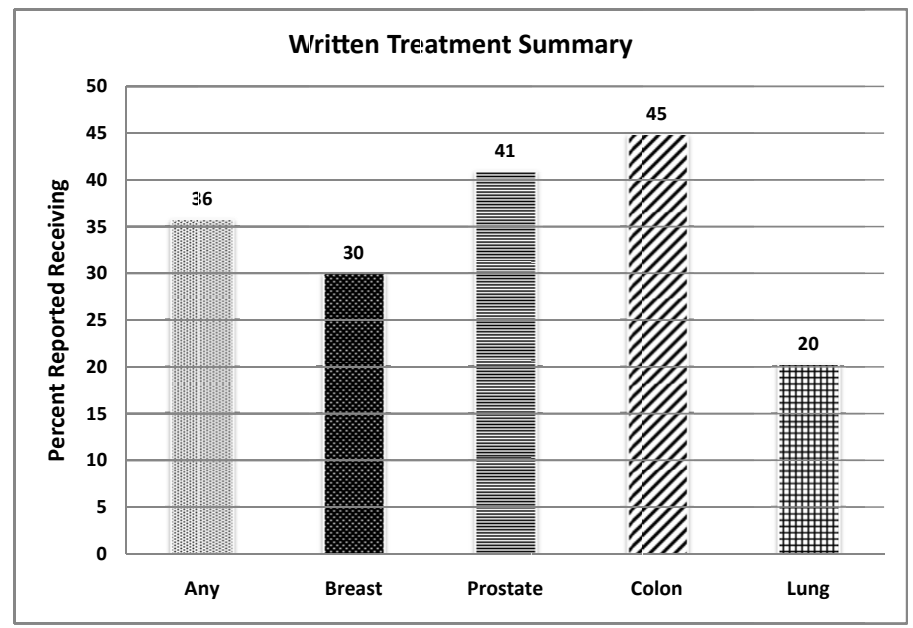

Figure 2. Rates of receipt of written treatment summary. 
Table 2. Survivorship by cancer type.

\begin{tabular}{|c|c|c|c|c|c|c|}
\hline & \multicolumn{2}{|c|}{ Unadjusted } & \multicolumn{2}{|c|}{ Model 1* } & \multicolumn{2}{|c|}{ Model $2^{* k}$} \\
\hline & OR & $95 \%$ CI & OR & $95 \%$ CI & OR & $95 \% \mathrm{CI}$ \\
\hline Lung & \multicolumn{2}{|c|}{ REF } & \multicolumn{2}{|c|}{ REF } & \multicolumn{2}{|c|}{ REF } \\
\hline \multicolumn{7}{|c|}{ High quality of life ${ }^{1}$} \\
\hline Colon & 2.13 & $0.94-4.81$ & 2.03 & $0.88-4.66$ & 2.01 & $0.77-5.26$ \\
\hline Breast & 3.43 & $1.51-7.80$ & 3.59 & $1.55-8.33$ & 3.24 & $1.19-8.78$ \\
\hline Prostate & 3.36 & $1.48-7.61$ & 2.97 & $1.28-6.91$ & 2.54 & $0.98-6.62$ \\
\hline \multicolumn{7}{|c|}{ High physical health status ${ }^{1}$} \\
\hline Colon & 1.90 & $0.84-4.33$ & 1.88 & $0.83-4.29$ & 1.43 & $0.55-3.72$ \\
\hline Breast & 3.04 & $1.36-6.79$ & 3.07 & $1.37-6.88$ & 2.08 & $0.78-5.53$ \\
\hline Prostate & 3.51 & $1.57-7.88$ & 3.31 & $1.46-7.49$ & 2.3 & $0.90-5.90$ \\
\hline \multicolumn{7}{|c|}{ High mental health status ${ }^{1}$} \\
\hline Colon & 1.35 & $0.69-2.65$ & 1.35 & $0.69-2.66$ & 1.37 & $0.61-3.04$ \\
\hline Breast & 1.77 & $0.93-3.38$ & 1.87 & $0.96-3.65$ & 1.6 & $0.71-3.61$ \\
\hline Prostate & 2.19 & $1.14-4.21$ & 2.08 & $1.08-4.03$ & 1.88 & $0.88-4.01$ \\
\hline \multicolumn{7}{|c|}{ Low worry cancer will come back ${ }^{2}$} \\
\hline Colon & 1.46 & $0.74-2.86$ & 1.39 & $0.69-2.81$ & 0.99 & $0.49-2.00$ \\
\hline Breast & 1.75 & $0.94-3.26$ & 1.93 & $1.02-3.65$ & 1.37 & $0.72-2.61$ \\
\hline Prostate & 2.65 & $1.39-5.06$ & 2.4 & $1.25-4.64$ & 2 & $1.02-3.92$ \\
\hline \multicolumn{7}{|c|}{ High cancer caused financial problems ${ }^{3}$} \\
\hline Colon & 0.47 & $0.25-0.89$ & 0.46 & $0.24-0.87$ & 0.57 & $0.29-1.11$ \\
\hline Breast & 0.52 & $0.29-0.94$ & 0.45 & $0.25-0.81$ & 0.62 & $0.34-1.14$ \\
\hline Prostate & 0.26 & $0.14-0.49$ & 0.3 & $0.16-0.56$ & 0.31 & $0.16-0.60$ \\
\hline
\end{tabular}

Legend: (1) rating of "good, very good, or excellent"; (2) Frequency of cancer worry "never, rarely or sometimes"; (3) Degree that cancer caused financial problems" a lot or some".

*Model 1: Adjustment for age, gender (colon and lung cancer only), and marital status.

**Model 2: Adjusted for recent cancer recurrence, surgery as primary cancer treatment, and treatment within the past 12 months

centers reported that only $43 \%$ of all centers were routinely using SCPs and none of these contained the required elements outlined by the IOM [15] Another study by Hill-Kayser et al. found that only $12 \%$ of cancer survivors reported receiving survivorship information $[12,13]$. Our study found that overall, $36 \%$ of survivors reported receiving a treatment summary, but only $20 \%$ of lung cancer survivors. This is lower than the NCI study but likely more reflective of real world practice. These low rates of use may be due to lack of evidence of improved patient reported outcomes associated with the use of SCPs despite relatively high interest among patients and providers.

Our study has several limitations. The National Health Interview Survey is a robust population health evaluation tool, however it is still subject to sampling bias and limitations in extrapolating results to the entire US population. Additionally, the data are self-reported and subject to recall bias that may vary by time since diagnosis and cancer type. The self-reported nature of the assessment of quality of life also does not use validated instruments. Nonetheless, the findings are consistent with other published reports among cancer survivors on the whole and attempts to extend our knowledge further by exploring differences between cancer types to better inform interventions aimed at this special population. The field of survivorship research has shown tremendous growth over the past two decades, however there is an inequitable distribution of research on cancer survivors based on the population by cancer type. For instance, prostate cancer represents $20 \%$ of cancer survivors but only $5 \%$ of survivorship research efforts. Conversely, breast cancer survivors represent $22 \%$ of the population, but $40 \%$ of the survivorship research efforts [7]. Intervention tools aimed at improving survivorship care have yielded mixed results even when limited to breast cancer patients. But application of these tools to other cancer types may also be problematic and off target. Further study should be undertaken to discern the needs of cancer survivors with equal emphasis on common themes as well as difference among cancer types in order to embrace a more tailored and patient-centered approach to care.

\section{Conflicts of interest}

The authors have no conflicts of interested to disclose.

\section{Acknowledgements}

This work was funded by NIH/NCATS National Center for Research Resources 2 KL2 TR000421-06 KL2 Scholar ITHS Multidisciplinary Clinical Research Training Program (Author: Backhus).

Views expressed in this article are those of the authors and do not necessarily reflect the position or policy of the Department of Veterans Affairs or the United States Government.

\section{References}

1. Bellizzi KM, Mustian KM, Palesh OG, Diefenbach M (2008) Cancer survivorship and aging : moving the science forward. Cancer 113: 3530-3539. [Crossref]

2. Bellury LM, Ellington L, Beck SL, Stein K, Pett M, et al. (2011) Elderly cancer survivorship: an integrative review and conceptual framework. Eur J Oncol Nurs 15: 233-242. [Crossref]

3. Cancer ACoSCo (2012) Cancer Program Standards 2012: Ensuring Patient-Centered Care v1.2.1. In: Editor (ed)^(eds) Book Cancer Program Standards 2012: Ensuring Patient-Centered Care v1.2.1. American College of Surgeons, City.

4. Clauser SB, Arora NK, Bellizzi KM, Haffer SC, Topor M, et al. (2008) Disparities in HRQOL of cancer survivors and non-cancer managed care enrollees. Health Care Financ Rev29: 23-40.[Crossref]

5. De Boer AG, Taskila T, Ojajärvi A, van Dijk FJ, Verbeek JH (2009) Cancer survivors and unemployment: a meta-analysis and meta-regression. JAMA 301: 753-762. [Crossref]

6. Elliott J, Fallows A, Staetsky L, Smith PW, Foster CL, et al. (2011) The health and 
well-being of cancer survivors in the UK: findings from a population-based survey. $\mathrm{Br}$ J Cancer 105 Suppl 1: S11-20.[Crossref]

7. Harrop JP, Dean JA, Paskett ED (2011) Cancer survivorship research: a review of the literature and summary of current NCI-designated cancer center projects. Cancer Epidemiol Biomarkers Prev 20: 2042-2047.[Crossref]

8. Hays RD, Smith AW, Reeve BB, Spritzer KL, Marcus SE, et al. (2008) Cigarette smoking and health-related quality of life in Medicare beneficiaries. Health Care Financ Rev29: 57-67.[Crossref]

9. Hewitt M, Breen N, Devesa S (1999) Cancer prevalence and survivorship issues: analyses of the 1992 National Health Interview Survey. J Natl Cancer Inst91: 14801486.[Crossref]

10. Hewitt M, Rowland JH (2002) Mental health service use among adult cancer survivors: analyses of the National Health Interview Survey. J Clin Oncol20: 4581-4590. [Crossref]

11. Hewitt M, Rowland JH, Yancik R (2003) Cancer survivors in the United States: age, health, and disability. J Gerontol A Biol Sci Med Sci58: 82-91.[Crossref]

12. Hill-Kayser CE, Vachani C, Hampshire MK, Jacobs LA, Metz JM (2009) An internet tool for creation of cancer survivorship care plans for survivors and health care providers: design, implementation, use and user satisfaction. $J$ Med Internet Res 11 : e39.[Crossref]
13. Hill-Kayser CE, Vachani C, Hampshire MK, Jacobs LA, Metz JM (2009) Utilization of internet-based survivorship care plans by lung cancer survivors. Clin Lung Cancer 10: 347-352.[Crossref]

14. Ko CY, Maggard M, Livingston EH (2003) Evaluating health utility in patients with melanoma, breast cancer, colon cancer, and lung cancer: a nationwide, populationbased assessment. J Surg Res 114: 1-5.[Crossref]

15. Salz T, Oeffinger KC, McCabe MS, Layne TM, Bach PB (2012) Survivorship care plans in research and practice. CA Cancer J Clin62: 101-117.[Crossref]

16. Schlairet M, Heddon MA, Griffis M (2010) Piloting a needs assessment to guide development of a survivorship program for a community cancer center. Oncol Nurs Forum37: 501-508.[Crossref]

17. Shi Q, Smith TG, Michonski JD, Stein KD, Kaw C, et al. (2011) Symptom burden in cancer survivors 1 year after diagnosis: a report from the American Cancer Society's Studies of Cancer Survivors. Cancer 117: 2779-2790.[Crossref]

8. Siegel R, DeSantis C, Virgo K, Stein K, Mariotto A, et al. (2012) Cancer treatment and survivorship statistics, 2012. CA Cancer J Clin62: 220-241.[Crossref]

19. Smith AW, Reeve BB, Bellizzi KM, Harlan LC, Klabunde CN, et al. (2008) Cancer, comorbidities, and health-related quality of life of older adults. Health Care Financ Rev 29: 41-56.[Crossref]

20. Yabroff KR, Lawrence WF, Clauser S, Davis WW, Brown ML (2004) Burden of illness in cancer survivors: findings from a population-based national sample. $J$ Nat Cancer Inst96: 1322-1330.[Crossref]

Copyright: (C2016 Backhus LM. This is an open-access article distributed under the terms of the Creative Commons Attribution License, which permits unrestricted use, distribution, and reproduction in any medium, provided the original author and source are credited. 